\title{
Foreword
}

\section{Physical and Mechanical Metallurgy of Shape Memory Alloys for Actuator Applications}

Although shape memory alloys (SMA) have been around for several decades, new opportunities and applications have emerged for SMA-based actuators, especially in the aerospace, automotive, oil, and gas industries. These emerging applications have resulted in a significant change in the philosophy of materials development, engineering, and design. In this regard, the effects of variables, such as compositions, microstructures, specimen shapes, magnetic fields, stress and temperature cycles, and processing on important SMA properties, are critical to an insightful understanding of their behavior as actuator materials. In addition, the development of new high-temperature SMAs and advanced magnetic SMAs requires considerable detailed characterization of their properties to suitably qualify them for actuator applications.

In view of the growing importance of SMA actuators, it was felt by the organizers that there was a need to organize a symposium on the subject to provide a forum for experts from academia, government, and industry to present their latest research findings and interact with each other. The planning and organizational efforts for the symposium commenced in late 2008, and culminated in the hosting of an international symposium entitled Physical and Mechanical Metallurgy of Shape Memory Alloys for Actuator Applications. The symposium, which was sponsored by the Joint Mechanical Behavior of Materials Committee of ASM International and The Minerals, Metals and Materials Society (TMS), was held as part of the TMS 2011 Annual Meeting \& Exhibition, San Diego, CA, February 27-March 3,2011 .

The conference covered topics on alloy development, characterization, processing, modeling, and applications. The approximately 90 papers presented at the symposium were organized into eight sessions: (1) Characterization of Shape Memory Alloys-Deformation Behavior, (2) Characterization of Shape Memory Alloys-Structure-Property Relationships, (3) Characterization of Shape Memory Alloys-Microstructural Transformation, (4) Fundamental and Engineering Modeling of Shape Memory Alloys, (5) Alloy Design and Development, (6) Effect of Processing on the Properties of Shape Memory Alloys, (7) Applications of Shape Memory Alloys, and (8) Poster Session. Two plenary lectures and 23 invited talks were presented at the symposium. Some of these papers are now included in this issue of Metallurgical and Materials Transactions $A$ as a collective series.

We thank the Joint Mechanical Behavior of Materials Committee and TMS for sponsoring and hosting the symposium; Ms. Christina Raabe Eck, Ms. Marla Boots, Ms. Christina Woods, and Mr. Robert Makowski of TMS for their assistance with the organizational efforts; Professor David Laughlin, Editor, Metallurgical and Materials Transactions A, for allowing us to publish the symposium papers in his journal; and Ms. Dora Moscatello for her help in coordinating the review and publication of these papers.

S.V. Raj, Chair

F.T. Calkins

I. Karaman

S. Miyazaki

R.D. Noebe

R. Vaidyanathan 